\title{
11. Ludo-epistemology: Playing with the rules in citizen science games
}

\author{
René Glas and Sybille Lammes
}

\begin{abstract}
In their chapter, Glas and Lammes critically investigate the limitations of citizen science game design when it comes to having amateurs playfully participate in the production of scientific knowledge. Moving away from the traditional distance between the scientist as expert and the citizen as layperson, and between science as serious and play as trivial, they argue for a recognition of play as fundamental to the scientific endeavor and see rule breaking and bending as an essential part of this process. From this perspective, they consider an approach to citizen science game design that includes playing with the rules as a more critical way of having citizens think about and participate in science.
\end{abstract}

Keywords: Citizen science games, production of knowledge, cheating, rules of play, theorycrafting, ludo-epistemology

Industry terms like 'serious games' and 'gamification' convey, or at least suggest, that games and other forms of playful media can be designed and implemented in such a way that users are not just entertained, but also educated, persuaded, or trained by engaging them in playful conduct. Citizen science games take this one step further, as such games implicitly or explicitly invite non-professionals to contribute to scientific research and knowledge production through play. Yet, as we will argue in this chapter, we need to reconsider what the concept of citizen science games can mean. Although we appreciate that existing citizen science games are highly valuable tools for (meta)data gathering, fact checking, and problem solving, we think that there is need for a different type, or understanding, of citizen science games. Moving away from a classical model based on the distinction

Glas, R., S. Lammes, M. de Lange, J. Raessens, and I. de Vries, eds. 2019. The Playful Citizen. Civic Engagement in a Mediatized Culture. Amsterdam: Amsterdam University Press. DOI: 10.5117/9789462984523/CH11 
between the scientist as expert and citizen as layperson, we call for a new kind of citizen science game that goes beyond such strict boundaries and truly merges the two positions by recognizing the play in science and the potential of citizens to critically reflect upon and engage with science through play.

To do so, we investigate how play can be a means of critical intervention and how citizen science games can provide players agency in bending or breaking established rules, as processes inextricably linked to both play and knowledge production. Using both game studies as well as a philosophy of science perspective, we argue that not just play, but also playing with rules offers new venues of critical engagement for the production of knowledge. Play can be a powerful means for opening up scientific endeavors to 'amateurs,' and the directly related activities of rule breaking/bending opens up new perspectives for designing alternative citizen science games.

In its classical form, citizen science is often defined as "a form of research collaboration involving members of the public in scientific projects to address real-world problems" (Wiggins and Crowston 2011, 1). As Bonney et al. $(2009,978)$ have pointed out in relation to biology, the notion of voluntary public participation in scientific research has a long history, with early examples in biological research going back to the late nineteenth century. The contemporary concept of citizen science, with "its integration of explicit and tested protocols for collecting data, vetting of data by professional [scientists], and inclusion of specific and measurable goals for public education," they argue, only evolved over the past few decades (2009, 978). Digital games, being rule-based systems, are a good fit for this systematic collection and analysis of data and, being an increasingly popular medium, are often considered to be a good platform for educational purposes of knowledge advancement as well (see Squire 2011). A host of citizen science games have appeared over the past several years, including Foldit (University of Washington Center for Game Science/Department of Biochemistry 2008), Phylo (McGill Centre for Bioinformatics 2010), EteRNA (Carnegie Mellon University and Stanford University 2010), Quantum Moves (UA Ideas CODER 2012), Fraxinus (The Sainsbury Laboratory 2013), and Stall Catchers (EyesOnALZ 2016), which are based on such principles. Many of these games can be seen as a form of human-computer interaction, where human activity is crowd-sourced to help computer systems solve problems by, for instance, interpreting data it cannot manage by itself. Yet, games relying on human-based computation via crowd-sourcing, like "games with a purpose" or GWAPs (Von Ahn 2006) or the games created through the Metadata Games platform (Flanagan et al. 2013), are not necessarily 
all citizen science games. ${ }^{1}$ Dickinson and Bonney, argue for instance, that scientific interests, and the aim to publish results based on project data, should be part of a citizen science project from the outset, adding that "if researchers have no interest in the project, or in analyzing its data, then we would consider a project unsuccessful" $(2012,2){ }^{2}$ Citizen science games like the ones mentioned above were initiated by the scientific community, and have indeed yielded publications in high-ranking journals (Hand 2010; Cossins 2013). One such study published in Nature dealing with the playercreated scientific breakthroughs concerning protein-folding puzzle game Foldit even mentions the players (as 'Foldit Contenders Group' and 'Foldit Void Crushers Group') as co-authors (Khatib et al. 2011). Such publications show the potential of using games to engender new productive links between citizen science and play.

Foldit is often mentioned as an example of a citizen science game (see also Chapters 12 and 13 in this volume), yet it represents in our view just one pathway for this 'genre.' To be sure, we do not deny that games like Foldit can yield interesting crowd-sourced data and analyses, but at the same time we should be aware of the ideological, pragmatic, and missionary underpinning of such games: that 'science should be brought to the people,' so then, why not through play. As a provocative experiment, we ask ourselves: what happens if we embrace the notion that 'real' scientists are citizens as well, the latter being pivotal to how philosopher Feyerabend understood citizen science (1978). By breaking away from an assumed asymmetry between scientists and citizens, we want to explore the idea that doing science through play can be fruitful not only to enroll 'citizen-laymen,' but that it also can encourage citizens to more critically scrutinize scientific processes. In other words, we have to change our assumptions of what citizens are and can do in relation to science. Such a re-evaluation enables us to rethink the potential of citizen science games as critical and creative tools for engagement.

1 An interesting discussion is whether or not most citizen science games can actually be considered traditional games according to formal definitions (see Juul 2005) or should be seen as gamified media, in which gamification stands for "the use of game elements in a non-game contexts" (Deterding, Dixon, Khaled, and Nacke 2011, 2). While the distinction is relevant for formal analysis and design-related questions, as both elicit active engagement from users through playful interaction, which is the main goal of citizen science games, we do not engage with this distinction here, since we are primarily interested in the relation between play and knowledge production.

2 The game Citizen Science (Filament Games and Squire 2013), which aims to teach scientific literacy through play (see Gaydos and Squire 2010) would not adhere to this definition. While this educational goal is also part of the citizen science movement, this game does not invite the public to directly engage or collaborate in scientific research. 


\section{Scientists play too}

Our reconsideration of the relation between, citizens, science, and play, also includes a recognition that scientist are citizens, which means 'real' scientific practices can be playful. To some it may be obvious and to others it may sound far-fetched, but scientists also play and they actually love it. Play may indeed seem, at first glance, the very antipode to science; as a popular kind of fictional entertainment, play seems irrational, infantile, and unsophisticated, all qualifications that scientists would rather avoid than be associated with. Yet, play is a major driving force of knowledge production and not necessarily opposed to seriousness (see Ehrmann, Lewis, and Lewis 1968). As play theorist Sutton-Smith argued in 'The playful modes of knowing' (1970), play is a fundamental way of obtaining knowledge. He maintained that play is an intelligent practice that helps us to explore, test, and evaluate situations. According to Sutton-Smith, "all forms of play are transformations of one or other of four basic modes by which we know the world," and the modes he recognized are: "copying," "analyze and seek causes," "predicting," and "synthesis" (1970, 2). It does not require much imagination to translate these leading principles of knowing through play to scientific practices, such as scientific exploration, testing, and reproduction. Similarly, philosopher of science David Hull maintains that play is an important characteristic of scientists' practices and describes this innate quality as "play behavior carried to adulthood" $(1988,305)$. In economic models of scientific communities, scientists are even seen as reward-driven gamers and the research they conduct as "a kind of game, a puzzle-solving operation in which the solution of the puzzle is its own reward" (Hagstrom 1965 , quoted in Stephan, 1996, 1203). Although we are wary about drawing a direct connection between economical systems, science, and games, such observations do show that play and science are not or do not need to be in contention with each other. Play is actually key to processes of exploration and is therefore also an important part of techno-scientific change. Play may thus be crucial for developing the frame of mind that is needed for 'serious' social practices such as knowledge production (Csíkszentmihályi 2009; Mainemelis 2010).

Yet, play is also often viewed as infantile, trivial, serendipitous and at times even insane. These qualities seem rather far removed from how we want to perceive good and ethical scientific practices. This may be an important reason why scientists shy away from showing their playful sides in public. Or, as chemist Pierre Laszlo writes in a personal note in American Scientist: 
Play in scientific research is seldom discussed in print. Perhaps we scientists take it for granted. Or maybe we are a little self-conscious and try to hide it from others. After all, we don't want taxpayers to think they are subsidizing adults who are acting like a bunch of kids, thereby squandering hefty amounts of public money. Play in science is thus an elusive and difficult topic. (Laszlo 2004, 389)

There is a great difference between how science and artefacts are presented to the 'outer world,' and how they are actually produced in workplaces such as laboratories. This is important to acknowledge if we want to open new potential for citizen science games. Play is crucial to processes that precede the formation of scientific artefacts, but we, as 'normal' citizens, are not supposed to see this. Playing is an intrinsic part of scientific knowledge production, yet it is mostly covered up, or 'black-boxed' for outsiders, for the reasons sketched above. It is, however, important to acknowledge the asymmetry between the insider and the outsider when we want to understand what citizen science games are about and how they could be designed in different and innovative ways. If we want to make games that engage citizens critically, we have to acknowledge that play is not antipodal to science and that scientists are actually civium ludens as well. Then, citizen science games are no longer a contradiction in terms, but actually lay bare what science really is about. Moreover, it suggests that games can have the potential to become powerful tools for engaging citizens critically, encouraging them to reflect upon and to transform scientific processes through play.

As anthropologists of science Latour and Woolgar already showed in their seminal study Laboratory life: The construction of scientific facts (1979), production centers of techno-scientific artefacts are by no means the clean, tidy, and rational places they seem from the outside. Artefacts are social outcomes of complex processes in which actors form ever-changing alliances that are at times messy, 'warm,' and trivial. Sometimes we, as outsiders of such bastions of knowledge production, catch a glimpse of this side of science, albeit often in the shape of myths. A myriad of anecdotes spring to mind of stories of scientists' imagination or "mind-play" (Sutton-Smith 2001). To name just a few, one includes Nobel laureate and play theorist John Nash (Nasar 1998), who allegedly suffered from 'insane' genius, or other stories of 'incubator' dreams like Kekul apparently dreaming about snakes, which helped him find the ring-shaped molecular structure of Benzene (Tweney 1996). Such narratives are passed to the 'normal' citizen as acts of visionary or even religious genius (Noble 2013) in which a "new force takes hold of the soul and directs it, toward theoretical insight" (Feyerabend, 1987a, 701). 
Although relying heavily on the romantic ideal of individual instead of collective creativity (Theodore 2010), these stories allow people outside the centers of knowledge production to at least catch a whiff of the less orderly and serious parts of laboratory lives and the (mind) play that is part and parcel of scientific endeavors.

If we accept that scientific practices can be playful ventures, we can instantly recognize instances when the rules were bent or broken. In its extreme form this becomes deviance, which is most often considered unruly, unethical, and unwanted behavior that, when detected, can lead to the subsequent end of play, and when applied to the 'real' world, the end of actual academic careers. From pseudo-science to hoaxes, from plagiarism to fraud - where scientists play, they also break or transgress rules. Far more than with games, deviance in science easily clashes with our notion that outsiders should be able to trust scientists. For instance, cheating in scientific practices is rightly seen as an indication of unethical, 'bad' scientific conduct, and it comes in many different shades and forms. As sociologist Bridgstock points out, there are many reasons for fraud, or cheating in science, such as strong beliefs in developed theories, but they can also include "career motivations and political views" (Bridgstock 1982, 364). Lesser forms of deviance, showing that fair play in academia is not always tenable, are highly common practices of (sexist) nepotism in peer-review systems in which we can recognize the (albeit sometimes unconscious) bending of rules in order to promote particular scientific schools, ideas, or gender relations (Wennerås and Wold 1997; Langfeldt 2001).

\section{Looking through the cracks}

As examples of cheating in science show, playing with the rules of scientific practices is not uncommon and varies in form and gravity. Judging from the sensational press coverages of floundering scientific projects, one could conclude that citizens love to see scientists cheat. This cultural fascination with failing and unethical science is related to the asymmetry that we described earlier. Similar to the myth of the insane and genius scientist, it brings to the surface what we deep down knew all along: scientists are human beings and citizens too. It points us to cracks in the plaster of the scientific bastions through which we can catch, albeit distorted, a glimpse of the game of science including its duplicitous, tricky, and deceitful sides. It reveals that scientific knowledge production is not at all aloof to deviance or playing with rules. Outside the closed fortresses of knowledge production, 
we are simultaneously fascinated, confused by, and estranged from what scientific practices entail.

We mention these examples to show how closed most techno-scientific strongholds are and how intrigued and scandalized we become when we witness the other "Janus face" (Latour 1993) of scientific practices in their less orderly forms. We also point this out because it is one of the rare moments we realize that scientists can play with rules to the extreme of cheating and being duplicitous. Yet, play can also be a highly ethical and productive element of techno-scientific change and acknowledging this may open new ways of overcoming the asymmetrical relationship between scientists and other citizens that is particularly important for developing innovative citizen science games. That bending the rules can be an important and positive element of knowledge production has been stressed by both philosopher of science Feyerabend, as well as by his less radical peer Thomas Kuhn (Bailin 1990). Feyerabend took a very uncompromising stance on how science could be revolutionized by calling for an anarchic epistemology in which rules were no longer a pre-given. Although probably both too radical and relativistic, his stance does provoke us to think differently about ingrained rules in science and how they can hinder new knowledge production as well as the development and design of true citizen science games. Or, as Feyerabend wrote himself in Farewell to reason (1987b) about his previous works $(1975,1978)$ :

In Against Method (AM) I argued that the customary accounts of scientific knowledge and scientific method are faulty and that scientists do not proceed 'rationally' in the sense of rationalist philosophers. In Science in a Free Society (SFS) I argued that the sciences are particular ways of gaining information and of interfering with the world, that there are other such ways and that these 'other' ways are satisfactory in the sense that they meet the material and spiritual needs of those who use them. I added that, like all institutions in a free society, the sciences should be subjected to a democratic control. (Feyerabend, 1987b, v)

Going beyond rationality and changing rules were important aims in Feyerabend's democratic project. He believed that bending or negotiating rules should be a crucial part of innovative scientific practices and could improve the quality and democratic value of science. In her article about science education entitled 'Creativity, discovery, and science education: Kuhn and Feyerabend revisited' (1990), Bailin points out that both Feyerabend and the influential philosopher of science Thomas Kuhn related the improvement 
of science (in Kuhn's case rational and 'progressive') to rule bending and rule breaking during creative processes. Through deviant ways of using rules in method and theory or even discarding them all together, paradigm shifts can occur:

Revolutionary science $[. .$.$] is characterized by a radical departure from the$ prevailing paradigm and the creation of a completely new one. It involves the overthrow of the presuppositions underlying the old paradigm and the establishment of a radically new framework. This new paradigm is not a logical continuation of the previous one, but involves a new way of viewing phenomena and is, thus, incommensurable with the old paradigm. The postulation and acceptance of the heliocentric view of planetary organization, would be an example of this kind of revolutionary science, upsetting the presupposition that centrality and fixity were necessary properties of the earth, and establishing a whole new framework for astronomical observation and theory. (Bailin, 1990, 35)

So, play is an important element of knowledge production in scientific workplaces, and negotiating or bending rules is also part of such processes and not necessarily a bad or unethical practice either. According to Feyerabend, it can even lead to innovative theories and methods that can be more democratic. If we want to come to a better and more symmetrical approach and understanding of citizen science games, such insights about the relation between play and the making of science are highly valuable. Playing — including playing with the rules of the game - and doing science have more in common than we may think at first glance, and the term citizen science games no longer seems to contain an internal contradiction when we take this perspective on board. Looking at existing citizen science games, which we will turn to next, paints a very particular picture of the freedom play is allowed.

\section{The dangers of the cheater}

Serious games generally have a very specific goal in mind. With citizen science games this is generating usable scientific data. Deviating from the preferred form of play might endanger such goals. It is for this reason that Sicart sees such forms of instrumental play as play "subordinated to the goals and rules and systems of the game" and "subordinate to reason, to the logic of achievement and progression externally determined by the 
player" (2011). For Sicart, this undercuts the more free-flowing, experimental nature of play, but within citizen science games limiting player freedom this is deliberate.

In order to understand how citizen science game design approaches the limits of play, we can first look at how it approaches cheating. In Clark Aldrich's The complete guide to simulations and serious games, for instance, we find a definition of cheating which reads: "to cheat is to purposefully subvert the intent and design of the experience," adding that it "reduces the effectiveness" of a game $(2009,262)$. This, as one could image, is problematic and needs to be prevented by design. This can be achieved in a gentle way by reminding players of the way a game is supposed to be played. In Eyewire, a game with the aim to map the human brain, players early on in the game receive a reminder not to initially worry about their mistakes: “[D]on't worry-even if you're wrong, you won't hurt science" (Wired Differently 2012). In literature on the design of citizen science games, the potential harm of cheating or other deviant play behavior concerns the quality of the data gathered and is discussed more directly. In an evaluation of the design process of Happy Match! (Syracuse University School of Information Studies \& Arts 2012), a citizen science game concerning animal classification, Crowston and Prestopnik note that they are unsure of the effects of adding game elements to citizen science, as "creating too strong an incentive to get a high score might lead to participants attempting to cheat or 'game' the system, diminishing rather than increasing data quality" $(2013,4)$. In another similar study of the design of Verbosity (Carnegie Mellon University 2006), a game using human-computation to collect common-knowledge facts, Speer, Havasi, and Surana show they are very aware of deviant behavior, stating that "we need to detect the patterns that indicate cheating, frustration, or 'bending the rules,' and remove or alter those assertions so that what remains is reasonable common sense knowledge" $(2010,106)$. The creators of Foldit mention cheating as part of the Gameplay Guidelines in their Community Rules overview on the game's website, stating that:

Any method of copying data from other players or external sources in order to increase your solo score is cheating. If you'd like to collaborate or expand upon another person's work, you must do so as an evolver. Cheating circumvents the intention of Foldit and jeopardizes its scientific goals. (Foldit Community Rules 2015)

The concerns mentioned above are understandable, and we do not want to trivialize efforts to curtail cheating or other potentially destructive 
forms of deviance. The whole point of citizen science games is to draw the public in to participate in research, not to cause potential havoc through unethical practices.

From a broader game design, but also from a cultural perspective, going beyond simply playing by the rules is not just common, the notion of rules themselves are also negotiable. It is important to remember there is a difference between the rules determined by a game's design (and thus the creators) and the rules that exist a priori to a game and/or are the result of social negotiation between players. The latter can be seen as 'implicit rules,' which concern "etiquette, good sportsmanship and other implied rules of proper game behavior" (Salen and Zimmerman 2004, 130). The rules can also be game specific or genre specific social codes of practice, like the "tenets laid down by individuals within the game who have no design power or automatically conferred authority" (MacCallum-Stewart 2011, 45). Therefore, whether or not something is considered deviant play or cheating is not always reliable from the perspectives of players. As Mia Consalvo points out in her book Cheating: Gaining advantage in videogames, a fixed definition of cheating is hard to provide, but on the whole, the overarching definition used by players is that cheating gives cheaters an unfair advantage $(2007,87)$. This advantage usually presides over others, but the notion of having an unfair advantage works in single-player games as well. Here, we find purist players for whom cheating simply means anything other than a solo effort in completing a game (Ibid., 88). In single-player games, a player can for instance use cheat codes or a walkthrough guide to get ahead in a game. As game scholar Julian Kücklich puts it:

The pleasure of any game depends on a balance between its rules and the freedom these rules leave the player for unconstrained interaction. Cheats can solve this dilemma by decreasing the perceived level of constraint in the game, thus setting the playing process in motion again. $(2004,5)$

In sum, what is considered as impermissible behavior with or within a game is not, or not merely, up to a game's designer —at least not from a player's perspective. What is considered unfair in the unfair advantage Consalvo mentions is an interpretation usually made by players concerning what they consider to be fair play.

With their emphasis on instrumental forms of play and relatively tight control on players' freedom to play otherwise, citizen science games might work well with the structured approach of scientific research. At the same time, to return to Sicart, they turn "the act of playing a game into a labor-like 
action, into work toward an externally decided, predetermined, and rational outcome designed by others than the players" (2011). While this might be the goal of citizen science games, for Sicart this contradicts the act of play:

Play, for being productive, should be a free, flexible, and negotiated activity, framed by rules but not determined by them. The meaning of a game, its essence, is not determined by the rules, but by the way players engage with those rules, by the way players play. (Ibid.)

Part of this freedom, this flexibility, and process of negotiation, is not just following the rules, but playing with them, and at times deviating from them. Again, we do not wish to argue that serious game design, or citizen science game design, is misguided for being overly instrumental. The point here is that examining different views on playful science can help to broaden the scope of citizen science games, as we will argue next.

\section{Another play on citizen science}

We are not arguing that existing types of citizen science games should be open to rule-breaking forms of play since these could potentially negatively impact the data generated by the players; what we are arguing is that the notion of citizen science games needs to be extended beyond the more narrow definition of primarily being human computation-based games. This would allow forms of citizen science that do more justice to the inherently playful nature of science discussed above. To do this, we want to look at practices within the genre of the massively multiplayer online role-playing game (MMORPG), in which we recognize exactly this notion of citizen science.

Successful games from this genre like World of Warcraft (Blizzard Entertainment 2004) have spawned massive communities of players who actively engage in participatory practices, like the creation of fan art, userinterface modifications, information databases, and so on. While some of these practices are expressive in nature, others are more instrumental, resulting in enhancing knowledge about and skill within the game. Among expert players, a specific type of investigative activity aims to obtain a better understanding of the inner workings of the game itself. This process, which has become known as theorycrafting, gives players a sense of access into and insight over the black box that is the game software, which is subsequently used to enhance tactical knowledge and skill for the most challenging gameplay situations the game has on offer. Among the tools for 
such investigations are user-interface modifications, also known as AddOns, which collect and visualize data generated by player actions within the game. Such AddOns are also created and distributed by the player community. Game scholar Torill Elvira Mortensen $(2008,208)$ distinguishes between two types, one is a deviant form of playing with the intended game design that is not counterproductive ("that which hinders personal progress") and the other is destructive ("that which ruins the progress of others"). But rather, it seems this is a form of productive deviation that excels or surpasses normal progress, resulting in what Glas calls "hyperproductive demystification" of a game: "instrumental progress going above and beyond the game's own challenges and fiction, both of which are deconstructed in the process" (2012, 90-100). Such forms of play notably change the experience and meaning of a game, creating new forms of, and norms for, playing the game. ${ }^{3}$

The reason for relating theorycrafting to citizen science is that the practice of theorycrafting brings to light a convergence of play with scientific habits of mind, with players displaying forms of scientific argumentation, model-based reasoning, and theory-evidence coordination (Steinkuehler and Chmiel 2006; Steinkuehler and Duncan 2008). For game scholar Karin Wenz, theorycrafting can, in fact, be seen as the "scientification" of gameplay, referring to a positivist approach to science using quantitative methods $(2013,181)$. Like the participants in the citizens science games discussed earlier, the player's theorycrafting practices here show "an engagement with data not primarily as part of research but as part of a leisure activity" $(2013,181)$. One could argue that theorycrafting does not involve a team of professional researchers who initiate the research process, analyze the data, and publish the results, primarily with public education in mind. The distinction between citizens and scientists, however, collapses here: the players instigate research through scientific means themselves. And they publish their results also, since reports of their findings are transferred to the public (i.e. the game community) in the form of discussions, formulas, tools, guides, and tutorials through various websites and knowledge databases dedicated to theorycrafting. From a game design perspective, we can say that, when a game like World of Warcraft allows players to collect and analyze

3 It should be noted that theorycrafting is not merely seen as beneficial to a game's community, as it also invites discussion on elitism between players (one well-known website for the theorycrafting community is even jokingly called 'Elitist Jerks') and can leads to social control and other disciplinary effects as players judge each other's play performance based on collected data rather than social skill or experience (Paul 2011; Glas 2012; Wenz 2013). For Wenz, "theorycrafting as a form as scientification of gameplay thus legitimizes both control mechanisms: control over the game and control over those who play it" $(2013,191)$. 
data about (parts of) its inner workings, we can see that scientific discursive practices can and often do emerge among the player base.

Probing the rules in games, then, can be productive for players. Within the field of game studies, it has also been recognized as productive for research purposes. While play as a dedicated method to investigate games is considered an essential part of digital game research (Aarseth 2003; Mäyrä 2008), Julian Kücklich emphasizes the advantages of using cheating as a methodological tool:

[It] allows us to reflect upon the presuppositions that we bring to games, no matter from which perspective we are studying them. It also enables us to identify blind spots in our research perspectives and thus discover new avenues of inquiry with regard to the phenomena we study. Perhaps even more importantly, taking into account unorthodox forms of play can help us recognize flaws in our theoretical models, which are so often built upon the experience of playing by the rules, rather than breaking them. $(2007,357)$

Researchers might, of course, already be prone to take such a position toward their research material. For people being asked to become citizen scientists, being confronted with few options to actually pursue such acts of reasoning and reflection as a result of experimentation within games, the benefits Kücklich mentions remain limited.

\section{Conclusion}

What we want to maintain in this chapter is that acknowledging the existing close relationship between more open forms of play (including potentially deviant ones) and science may be fruitful for broadening the scope of what we envisage as citizen science games, or citizen science play. This encourages or allows players to be reflexive about what the rules are and, by doing so, come to a better understanding what science is about—going beyond the presumed paradox of play and science. Play is not only a common practice in traditional centers of knowledge production, but is also productive in such settings. As such, it is not only a kind of preparation for the "real thing," as Sutton-Smith (1970) would have it, but also for being able to think 'out of the box'.

To make players productive rule-benders may sound like too radical a step to take, but it is after all a crucial intrinsic 'quality' of both playing 
and doing science. So why not use that potential to the full? It may be used in games as a way to make players into critical citizens who rise above the voyeurism of looking through the cracks that we described earlier in this chapter. Players can thus understand what scientific knowledge production is or could be and can also become more reflexive about how scientists as citizens operate, as well as becoming critical about the limitations of scientific engagement. It may also be used to create awareness that some kinds of rule bending are crucial to knowledge production, as Feyerabend claimed. Probing what is conceived as unbendable often leads to new insights. Feyerabend calls in this context for epistemological anarchism (1975) or, as Staley puts it, "abandoning any attempt to separate the good from the bad in science according to a fixed view of rationality" (1999, 603). We call for games that take ludo-epistemologies to heart, games that invite scientist to view themselves as citizens, and citizens to engage with the playful act of doing science.

\section{References}

Aarseth, E. J. 2003. Playing research: Methodological approaches to game analysis. Paper presented at The 5th international digital arts and culture conference, Melbourne, May 19, 2003.

Aldrich, C. 2009. The complete guide to simulations and serious games: How the most valuable content will be created in the age beyond Gutenberg to Google. San Francisco, CA: Pfeiffer.

Bailin, S. 1990. Creativity, discovery, and science education: Kuhn and Feyerabend revisited. Interchange 21 (3): 34-44.

Blizzard Entertainment. 2004. World of Warcraft. [Windows/OS X]. Blizzard Entertainment. Game.

Bonney, R., C. B. Cooper, J. Dickinson, S. Kelling, T. Phillips, K. V. Rosenberg, and J. Shirk. 2009. Citizen science: A developing tool for expanding knowledge and scientific literacy. BioScience 59 (11): 977-984.

Bridgstock, M.1982. A sociological approach to fraud in science.Journal of Sociology 18 (3): 364-383.

Carnegie Mellon University. 2006. Verbosity. [browser]. Carnegie Mellon University. Game.

Carnegie Mellon University and Stanford University. 2010. EteRNA [browser]. Carnegie Mellon University/Stanford University. Game.

Consalvo, M. 2007. Cheating: Gaining advantage in videogames. Cambridge, MA: The MIT Press. 
Cossins, D. 2013. Games for science: Playing scientist. The Scientist. http://www.the-scientist.com/?articles.view/articleNo/33715/title/ Games-for-Science.

Crowston, K., and N. R. Prestopnik. 2013. Motivation and data quality in a citizen science game: A design science evaluation. In Proceedings of the 46th Hawaii international conference on system sciences, Wailea, HI, January 7-10, 2013. Washington, DC: IEEE.

Csikszentmihalyi, M. 2009. Creativity: Flow and the psychology of discovery and invention. New York: HarperCollins.

Deterding, S., D. Dixon, R. Khaled, and L. Nacke. 2011. From game design elements to gamefulness: Defining "gamification". In Proceedings of the 15th international academic MindTrek conference: Envisioning future media environments, Tampere, September 28-30, 2011, 9-15. New York: ACM.

Dickinson, J. L., and R. Bonney. 2012. Introduction: Why citizen science? In Citizen science: Public participation in environmental research, eds. J. L. Dickinson and R. Bonney, 1-14. New York: Cornell University Press.

Ehrmann, J., C. Lewis, and P. Lewis. 1968. Homo ludens revisited. Yale French Studies 41: 31-57.

EyesOnALZ. 2016. Stall Catchers. [browser]. Human Computation Institute. Game.

Feyerabend, P. 1975. Against method. London: Verso Books.

-. 1978. Science in a free society. London: New Left Books.

—. 1987a. Creativity: A dangerous myth. Critical Inquiry 13 (4): 700-711.

- 1987b. Farewell to reason. London: Verso Books.

Filament Games and K. Squire. 2013. Citizen Science. [browser]. Filament Games. Game.

Flanagan, M., S. Punjasthitkul, M. Seidman, and G. Kaufman. 2013. Citizen archivists at play: Game design for gathering metadata for cultural heritage institutions. In Proceedings of the 2013 DiGRA international conference: DeFragging game studies, Atlanta, GA, August 26-29, 2013. http://www. tiltfactor.org/wp-content/uploads2/tiltfactor_citizenArchivistsAtPlay_ digra2013.pdf.

Foldit Community Rules. Foldit. http:/fold.it/portal/communityrules.

Gaydos, M., and K. Squire. 2010. Citizen science: Designing a game for the 21st century. In Interdisciplinary models and tools for serious games: Emerging concepts and future directions, ed. R. van Eck, 289-304. Hershey: Information Science Reference.

Glas, R. 2012. Battlefields of negotiation: Control, agency, and ownership in World of Warcraft. Amsterdam: Amsterdam University Press.

Hagstrom, W. O. 1965. The scientific community. New York: Basic Books. 
Hand, E. 2010. People power. Nature 466:685-687.

Hull, D. L. 1988. Science as a process: An evolutionary account of the social and conceptual development of science. Chicago, IL: University of Chicago Press. Juul, J. 2005. Half-real: Video games between real rules and fictional worlds. Cambridge, MA: The MIT Press.

Khatib, F., F. DiMaio, Foldit Contenders Group, Foldit Void Crushers Group, S. Cooper, M. Kazmierczyk, M. Gilski, et al. 2011. Crystal structure of a monomeric retroviral protease solved by protein folding game players. Nature Structural \& Molecular Biology 18:1175-1177.

Kücklich, J. 2004. Other playings: Cheating in computer games. Paper presented at The other players conference, Copenhagen, December 6-8, 2004.

-.2007. Homo Deludens: Cheating as a methodological tool in digital games research. Convergence 13 (4): 255-367.

Langfeldt, L. 2001. The decision-making constraints and processes of grant peer review, and their effects on the review outcome. Social Studies of Science 31 (6): 820-841.

Laszlo, P. 2004. Science as play. American Scientist 92 (5): 398.

Latour, B. 1993. We have never been modern. London: Harvester Wheatsheaf.

Latour, B., and S. Woolgar. 1979. Laboratory life: The construction of scientific facts. Princeton, NJ: Princeton University Press.

MacCallum-Stewart, E. 2011. Conflict, thought communities and textual appropriation in MMORPGs. In Online gaming in context: the social and cultural significance of online games, eds. G. Crawford, V. K. Gosling, and B. Light, 40-59. London: Routledge.

Mainemelis, C. 2010. Stealing fire: Creative deviance in the evolution of new ideas. Academy of Management Review 35 (4): 558-578.

Mäyrä, F. 2008. An introduction to game studies: Games in culture. London: Sage Publications.

McGill Centre for Bioinformatics. 2010. Phylo. [browser/Android]. Montreal: McGill University. Game.

Mortensen, T. E. 2008. Humans playing World of Warcraft: or deviant strategies? In Digital culture, play, and identity: A World of Warcraft reader, eds. H. G. Corneliussen and J. W. Rettberg. 203-224. Cambridge, MA: The MIT Press.

Nasar, S. 1998. A beautiful mind: A biography ofJohn Forbes Nash, Jr. New York: Simon and Schuster.

Noble, D. F. 2013. The religion of technology: The divinity of man and the spirit of invention. New York: Random House.

Paul, C. A. 2011. Optimizing play: How theorycraft changes gameplay and design. Game Studies 11 (2). http://gamestudies.org/1102/articles/paul. 
Salen, K., and E. Zimmerman. 2004. Rules of play: Game design fundamentals. Cambridge, MA: The MIT Press.

Sicart, M. 2011. Against procedurality. Game Studies 11 (3). http://gamestudies. org/1103/articles/sicart_ap.

Speer, R., C. Havasi, and H. Surana. 2010. Using Verbosity: Common sense data from games with a purpose. Paper presented at The 23 rd international Florida artificial intelligence research society conference, Daytona Beach, FL, May 19-21, 2010.

Squire, K. 2011. Video games and learning: Teaching and participatory culture in the digital age. New York: Teachers College Press.

Staley, K. W. 1999. Logic, liberty, and anarchy: Mill and Feyerabend on scientific method. The Social Science Journal 36 (4): 6o3-614.

Steinkuehler, C. A., and M. Chmiel. 2006. Fostering scientific habits of mind in the context of online play. In Proceedings of the 7 th international conference on learning sciences, Bloomington, IN, June 27-July 1, 2006, 723-729. New York: ACM.

Steinkuehler, C. A., and S. Duncan. 2008. Scientific habits of mind in virtual worlds. Journal of Science Education and Technology 17 (6): 530-543.

Stephan, P. E. 1996. The economics of science.Journal of Economic Literature 34 (3): 1199-1235.

Sutton-Smith, B. 1970. The playful modes of knowing. ERIC Institute of Education Sciences. http://eric.ed.gov/?id=EDo50806.

- 2001. The ambiguity of play. Cambridge, MA: Harvard University Press. Syracuse University School of Information Studies \& Arts. 2012. Happy Match! [browser]. Syracuse: Citizen Sort/Syracuse University. Game.

The Sainsbury Laboratory. 2013. Fraxinus. [Facebook]. The Sainsbury Laboratory. Game.

Theodore, D. 2010. Was Kekule's mind brainbound? The historiography of chemistry and the philosophy of extended cognition. Spontaneous Generations: AJournal for the History and Philosophy of Science 3 (1): 158-177.

Tweney, R. D. 1996. Presymbolic processes in scientific creativity. Creativity Research Journal 9 (2-3): 163-172.

UA Ideas CODER. 2012. Quantum Moves. [multi-platform]. University of Aarhus. Game.

University of Washington Center for Game Science/Department of Biochemistry. 2008. Foldit. [browser]. University of Washington. Game.

Von Ahn, L. 2006. Games with a purpose. IEEE Computer Magazine (June): 96-98.

Wennerås, C., and Wold, A. 1997. Nepotism and sexism in peer-review. Nature 387 (6631): 341-343. 
Wenz, K. 2013. Theorycrafting. Information, Communication \& Society 16 (2): $178-193$.

Wiggins, A., and Crowston, K. 2011. From conservation to crowdsourcing: A typology of citizen science. In Proceedings of the 44th Hawaii international conference on system sciences, Kauai, HI, January 4-7, 2011, 1-10. New York: ACM.

Wired Differently. 2012. Eyewire. [browser]. MIT. Game.

\section{About the authors}

René Glas is Assistant Professor of New Media and Digital Culture in the Department of Media and Culture Studies at Utrecht University. With a background in film and new media studies, his primary field is game studies, in which he teaches and writes about a variety of topics, including game history and culture, fan and participatory culture, cheating and other forms of deviant play, serious and pervasive games, and media comparison. Glas is a founding member of Utrecht University's Center for the Study of Digital Games and Play. His book Battlefields ofnegotiation: Control, agency, and ownership in World of Warcraft (2012) was published by Amsterdam University Press.

Sybille Lammes is Full Professor of New Media and Digital Culture at The Centre for the Arts in Society (LUCAS) at Leiden University. She has been a visiting Senior Research Fellow at The University of Manchester, and has worked as a researcher at the Centre for Interdisciplinary Methodologies at the University of Warwick, as well as the media studies departments of Utrecht University and the University of Amsterdam. Her background is in media studies and play studies, which she has always approached from an interdisciplinary angle, including cultural studies, science and technology studies, postcolonial studies, and critical geography. She is co-editor of Playful identities: The ludification of digital media cultures (Amsterdam University Press 2015), Mapping time (Manchester University Press 2018) and The Routledge handbook of interdisciplinary research methods (Routledge 2018). She is an ERC laureate and has been the principal investigator of numerous research projects. 